\title{
Prenatal diagnosis and treatment planning of congenital heart defects-possibilities and limits
}

\author{
Mathias Nelle, Luigi Raio, Mladen Pavlovic, Thierry Carrel, Daniel Surbek, \\ Matthias Meyer-Wittkopf \\ Berne, Switzerland
}

Background: Newborns with hypoplastic left heart syndrome (HLHS) or right heart syndrome or other malformations with a single ventricle physiology and associated hypoplasia of the great arteries continue to be a challenge in terms of survival. The vast majority of these forms of congenital heart defects relate to abnormal morphogenesis during early intrauterine development and can be diagnosed accurately by fetal echocardiography. Early knowledge of these conditions not only permits a better understanding of the progression of these malformations but encourages some researchers to explore new minimally invasive therapeutic options with a view to early pre- and postnatal cardiac palliation.

Data sources: PubMed database was searched with terms of "congenital heart defects", "fetal echocardiography" and "neonatal cardiac surgery".

Results: At present, early prenatal detection has been applied for monitoring pregnancy to avoid intrauterine cardiac decompensation. In principle, the majority of congenital heart defects can be diagnosed by prenatal echocardiography and the detection rate is $85 \%-95 \%$ at tertiary perinatal centers. The majority, particularly of complex congenital lesions, show a steadily progressive course including subsequent secondary phenomena such as arrhythmias or myocardial insufficiency. So prenatal treatment of an abnormal fetus is an area of perinatal medicine that is undergoing a very dynamic development. Early postnatal treatment is established for some time, and prenatal intervention or palliation is at its best experimental stage in individual cases.

Author Affiliations: Division of Neonatology (Nelle M), Division of Pediatric Cardiology (Pavlovic M), Department of Cardiac Surgery (Carrel T), and Department of Obstetrics and Gynecology (Raio L, Surbek D, Meyer-Wittkopf M), University Hospital Berne, Switzerland

Corresponding Author: Mathias Nelle, MD, Division of Neonatology, University Children's Hospital Berne, Effingerstr. 102, CH 3010 Berne, Switzerland (Tel: 0041 (0) 31 6321401; Email: mathias.nelle@insel.ch)

doi:10.1007/s12519-009-0003-8

(C)2009, World J Pediatr. All rights reserved.
Conclusion: The upcoming expansion of fetal cardiac intervention to ameliorate critically progressive fetal lesions intensifies the need to address issues about the adequacy of technological assessment and patient selection as well as the morbidity of those who undergo these procedures.

World J Pediatr 2009;5(1):18-22

Key words: congenital heart disease; fetal echocardiography; in utero cardiac palliation; postnatal intervention; prenatal diagnosis

\section{Introduction}

Heart defects are among the most common congenital malformations and the reported incidence is $0.5 \%-1 \%$ for all neonates. About half of these cardiovascular malformations are severe and usually require one or more surgical procedures in the neonatal period or during childhood. ${ }^{[1-10]}$ In Switzerland, every pregnant woman is entitled to two routine ultrasound scans by her obstetrician as part of routine prenatal care. $^{[11-13]}$ Besides determining fetal growth and the development of pregnancy, the function of the second and increasingly of the first scan is to identify malformations in the fetus. ${ }^{[14-19]}$ However, international and national prospective studies of prenatal "screening for heart defects" show that, up to now only 10\%-30\% of all cardiac defects or $20 \%-50 \%$ of discoverable cardiac lesions using the "four-chamber" ultrasound screening are actually diagnosed prenatally. ${ }^{[10,17-38]}$

If the neonatal mortality figures are considered in detail, it is striking that about $20 \%$ of all infant deaths and therefore $50 \%$ of these deaths can still be attributed to congenital heart disease or cardiovascular malformations. ${ }^{[11,18,19,33,34,39,40]}$ Interdisciplinary collaboration between neonatology, obstetric and prenatal medicine, pediatric cardiology, pediatric cardiac surgery and human genetics is essential to improve the baseline for perinatal treatment of these neonates, who are 
sometimes born seriously ill. If a heart defect has already been diagnosed prenatally, the infant with heart disease can usually be born spontaneously in the relevant perinatal or cardiac pediatric center and be treated and cared for without delay in the affiliated departments, thus avoiding a potentially hazardous postnatal transport. In many cases early interventional and/or surgical treatment is important for improving the prognosis of the neonate with heart disease besides using intensive care and medication. ${ }^{[10,11,18-20,23,27,35,36]}$

Several large studies have confirmed that not only perinatal management but also mortality and postoperative morbidity of affected newborns are markedly improved by the prenatal discovery of a transposition of the great vessels or hypoplastic left heart syndrome for example. ${ }^{[3,9,18,19,40-45]}$ Moreover, it is increasingly postulated that the postnatal treatment of cardiac malformations diagnosed in utero is delayed because morphological causes of these conditions (e.g., valve stenosis or dysplasia) can lead to, sometimes irreversible, secondary damage to sections of the heart and vessels without a primary malformation because intracardiac and intravascular hemodynamics are altered during the course of fetal growth compared to extra-uterine conditions. ${ }^{[4,6,12,13,18,19,25-27,30,37,45]}$ It is evident that these ideas about the genesis and prenatal progression of congenital heart malformations will have a crucial influence on future treatment plans. Discussion of possible developments in the next few years in the area of intrauterine treatment of certain obstructive heart defects may appear speculative at present. $^{[4-6,12,13,18,19,25-27,30,37,45,46]}$ Nevertheless, this article presents an early compressed and critical picture not only of current prenatal diagnostic and counselling possibilities but also of the first in utero case histories.

\section{Indications and limitations of prenatal cardiac diagnosis}

The problem of referral for specialized fetal echocardiography to screen for or confirm the diagnosis of congenital heart malformations is closely linked to the recognition of possible risk factors. In only about $10 \%-30 \%$ of fetuses with cardiac lesions, there are case-history related or (molecular) genetic risks (family history, teratogens in early pregnancy, maternal disease, new mutations detectable by molecular genetics). ${ }^{[16,18,19,21,22,32,34,35,37]}$ Since a risk factor can currently not be elicited either from the history or with conventional genetic or molecular genetic methods in $70 \%-90 \%$ of congenital heart defects, sonographic "abnormalities" on obstetric ultrasound screening during prenatal care point the way to effective use of the expertise available in pre- and perinatal centers. About $40 \%-50 \%$ of congenital heart defects can be discovered with just the four-chamber view in a lowrisk population, and additional examination of the outflow tracts and the two great arteries increases this rate to $65 \%-70 \%$ and encompasses all critical cardiac defects. ${ }^{[17-20,33,34,36,37]}$ However, this potential is currently by no means reached. In surveys of diagnosed malformations, congenital heart defects are markedly underrepresented compared with malformations of other organs, as they usually elude prenatal diagnosis. ${ }^{[10,11,16-20,24,28,33,36,38,40,47,48]}$ This may be due to interpretation of the scans of the heart taken from various angles, which demands good spatial awareness on the part of the examiner, and the assessment of even an optimal four-chamber view is highly dependent on the examiner's level of training. Diagnostic imaging of the fetal heart, as in all ultrasound imaging, depends greatly on the structure and extent of the overlying layers of maternal and fetal tissues. It is crucially important to record all malformations prenatally as exactly as possible, particularly in fetuses in which additional extracardiac malformations are found during prenatal investigations. If co-existing chromosome abnormalities are found, further stressful diagnostic measures or measures to prolong the pregnancy can be omitted because of the associated and sometimes substantial worsening of the fetal prognosis.

A growing group of patients who should be referred for more intensive prenatal diagnosis consists of those who deliberately forego chromosome testing (e.g., by amniocentesis or chorionic villus biopsy) because of the low risk of abortion despite the presence of an indication. Precisely in this group, definite ultrasonic exclusion of a fetal cardiac lesion is more important since a heart defect is present in approximately $50 \%$ of neonates with trisomy 21 , approximately $99 \%$ with trisomy 18 , approximately $90 \%$ with trisomy 13 and in $35 \%$ of fetuses with Noonan's syndrome. ${ }^{[18,19,20-22,28,33,34,40]}$ There have been only a few studies from German-speaking countries investigating the extent to which fetuses with congenital heart defects were actually detected in the course of general prenatal care and referred to a perinatal/pediatric cardiology center for further investigation, counselling and treatment planning..$^{[23,24,40]}$

The authors were entirely justified in concluding from their sobering results, showing, for instance, only a $10 \%$ prenatal detection rate for congenital right heart defects, that crucial progress would be achievable only by a marked improvement in both the level of training and the technical equipment of all involved in prenatal screening for malformations. The fact that the tentative external diagnosis of a possible heart defect can be confirmed in most fetuses investigated in regional 
prenatal medical centers emphasizes the importance of primary detection during prenatal care. ${ }^{[18-20,23,24,33,35,36]} \mathrm{In}$ principle, the majority of congenital heart defects can already be diagnosed by prenatal echocardiography and the detection rate is $85 \%-95 \%$ at tertiary perinatal centers. ${ }^{[9-11,16-20,23,24,35,36,44]}$ Nevertheless, in a few cases, exact and complete diagnosis is only successful postpartum as all current methods of intrauterine imaging of cardiac defects have numerous limitations including susceptibility to interference from fetal movements and marked dependence on fetal position. Segments of the heart overlaid by bony fetal thorax, spine or limb structures or parts of the heart situated posteriorly with oligo- or anhydramnios cannot be imaged especially at an advanced stage of pregnancy because of the absence of "fetal acoustic window". A further limitation is suboptimal or incomplete imaging of fetal heart segments with an extensive maternal stand-off distance or unfavorable placental or amniotic fluid conditions (e.g., deep intrauterine or deep intraabdominal fetal position).

Physicians specializing in pre- and perinatal medicine, neonatology, pediatric cardiology and pediatric cardiac surgery are confronted almost daily in their clinical practice with lack of clarity in prenatal cardiac diagnosis. Despite all these longfamiliar limitations, early prenatal detection of heart defects makes a crucial contribution to optimizing prenatal and perinatal management. It involves detailed interdisciplinary counselling of the parents, possibly prenatal chromosome testing, ultrasound exclusion of extracardiac malformations, selection of the place and time of delivery in a perinatal or pediatric cardiology center and the ensurance of immediate interventions for critical heart lesions. Prenatal establishment of a cardiac defect on its own without pediatric cardiological/pediatric cardiac surgical counselling about all aspects of pre- and postnatal prognosis and treatment options not only leads to considerable anxiety for the parents but also may jeopardize the continuation of pregnancy in individual cases.

\section{In utero progression of congenital heart defects}

Postnatal pediatric cardiology studies have shown that only a few heart defects improve or heal spontaneously over time without intervention (e.g., spontaneous closure of muscular ventricular septal defects). In contrast, the majority of complex congenital lesions show a steadily progressive course including subsequent secondary phenomena such as arrhythmias or myocardial insufficiency. With valve stenosis/atresia diagnosed early, an increase in ventricular remodelling (sometimes irreversible endo- and/or myocardial secondary damage of the fetal heart) is often already apparent in utero. Moreover, the reduction in blood flow because of high-grade valve stenosis/atresia in the vascular bed downstream leads to diminished and often asymmetrical vessel growth with secondary (congenital) vessel hypoplasia. Since the early days of prenatal echocardiography diagnosis, innumerable reports have been published about intrauterine progression and increased abortion and stillbirth rates in fetuses with heart defects. ${ }^{[2,5,6,18,25,27,30,32,37,45,46]}$ In the postnatal pediatric cardiological/pediatric cardiac surgery, it would be crucially important in the prenatal situation not only to diagnose cardiac defects as early as possible but also to treat them, thus avoiding secondary irreversible organ damage.$^{[46]}$ However, the corresponding cardiac structures of the fetus are accessible to many diagnostic and therapeutic procedures only at a more advanced gestational age (after the 18th week of pregnancy). With most cardiac defects, however, the organ damage is already considerable at the time of prenatal diagnosis and can no longer be corrected even by an intrauterine procedure.

\section{Minimally invasive fetal therapy}

Prenatal treatment of an abnormal fetus is an area of perinatal medicine that is undergoing a very dynamic development. Because of the rapid miniaturization of many endoscopes and cannula systems, an increasing number of fetal diseases that progress in utero are becoming accessible to prenatal treatment. $[1,7,27,30,31,37,39,43,45-48]$

For instance, with the aid of fetoscopically monitored laser coagulation, it is possible to interrupt communicating vascular anastomoses in the placenta in twin-to-twin transfusion syndrome. ${ }^{[7,33,47,48]}$ Experience with more extensive fetoscopic procedures on the fetus such as temporary in utero palliation of diaphragmatic hernias, myelomeningoceles or distal urinary tract obstruction is currently limited to a few centers in the world. The sometimes much milder secondary damage reported in these fetuses sounds hopeful although these experimental methods have not become part of routine care to date because of lack of long-term results with regard to comprehensive postnatal pediatric surgical/ pediatric urological/neurosurgical expertise. . $^{[1,15,33,39,47,48]}$ In keeping with the "early correction" aims of modern postnatal pediatric cardiac surgery, a few prenatal cardiac interventions were even performed on human fetuses. ${ }^{[6,14,18,19,27,37,45]} \mathrm{Up}$ to now, ultrasound-guided transabdominal or transthoracic puncture of the fetal heart in order to introduce a dilating catheter, which was then advanced into the stenotic valve, has been predominantly favored. Of the first 13 fetuses with so-called critical aortic valve stenosis, in whom 
such an intrauterine intervention was performed and analysed worldwide, only 1 fetus has survived a longterm. ${ }^{[28,29,37,39]}$ More recent follow-up studies, some still ongoing, appear to show a higher success and a higher survival rate. ${ }^{[6,27,45]}$

\section{Unanswered questions}

Apart from the technical difficulties, a series of questions must be discussed in connection with the optimal outcome in fetuses with heart defects that are progressive while still in utero. The natural course of heart defects detected in utero requires further intensive study as stabilization or lack of progression in the prenatal situation can be described for some of these defects with modified outcome analysis so that caution is warranted with any intrauterine procedures that might cause premature birth compared to the lower-risk postnatal operations. ${ }^{[5,6,12-14,25-27,30,32,37,42,45,46,48]}$ The possibly favorable prognostic influence on the patients of bringing forward the timing of these techniques must be confirmed in the next few years by well-designed studies. Fetuses with pulmonary valve atresia and postpartum catheter intervention can demonstrate a marked increase in right-ventricular dimensions including the possibility of biventricular palliation. Careful and sufficiently long pre- and postnatal documentation of individual cases together with collection and analysis of data in international registers is crucial. It is only by coordinating the efforts of selected national and international centers that scientifically confirmed progress in this area of interventional perinatal medicine can be expected.

\section{Conclusion}

In the not too distant future, the earlier interventions presented in this review article will supplement the known conventional postnatal treatment modalities available for a few of the cardiac defects that follow a progressive prenatal course. For physicians working in the area of pre- and perinatal medicine, it will therefore become increasingly difficult in the coming next years to give correct advice on procedures when these pregnant women are referred to them. To assist in decision-making, evaluation studies must urgently be initiated in centers specializing in the diagnosis and treatment of infants with heart disease. However, there is a particular requirement for the interdisciplinary counselling and psychological support of parents before, during and after the treatment. Comprehensive information about the nature of the disease and the probable prognosis depending on the time of treatment including all intervention-related risks must be provided by a consortium of prenatal physicians, pediatric cardiologists and cardiac surgeons. Otherwise, scientific medicine would be open to the reproach that it is further inflating the interdisciplinary diagnosis and treatment apparatus without sufficiently validating it or making it patient-oriented.

\section{Funding: None.}

Ethical approval: In overall all of our studies are approved by the Ethical Committee of the University Hospital Berne and the Canton Berne. In the special case of a review article no approval is needed.

Competing interest: No benefits in any form have been received or will be received from a commercial party related directly or indirectly to the subject of this article.

Contributors: Nelle M proposed the manuscript and wrote the first draft. All authors contributed to the intellectual content and appoved the final version. Meyer-Wittkopf $\mathrm{M}$ is the guarantor.

\section{References}

1 Aaronson OS, Tulipan NB, Cywes R, Sundell HW, Davis $\mathrm{GH}$, Bruner JP, et al. Robot-assisted endoscopic intrauterine myelomeningocele repair: a feasibility study. Pediatr Neurosurg 2002;36:85-89.

2 Allan LD. Cardiac anatomy screening: what is the best time for screening in pregnancy? Curr Opin Obstet Gynecol 2003; 15:143-146.

3 Allan LD, Apfel H, Printz B. Outcome after prenatal diagnosis of the hypoplastic left heart syndrome. Heart 1998;79:371-373.

4 Allan LD. Evolution of echocardiographic findings in the fetus. Circulation 1997;96:391-392.

5 Allan LD. The outcome of fetal congenital heart disease. Semin Perinatol 2000;24:380-384.

6 Arzt W, Tulzer G, Aigner M, Mair R, Hafner E. Invasive intrauterine treatment of pulmonary atresia/intact ventricular septum with heart failure. Ultrasound Obstet Gynecol 2003; 21:186-188.

7 Banek CS, Hecher K, Hackeloer BJ, Bartmann P. Longterm neurodevelopmental outcome after intrauterine laser treatment for severe twin-twin transfusion syndrome. Am J Obstet Gynecol 2003;188:876-880.

8 Bonnet D, Coltri A, Butera G, Fermont L, Le Bidois J, Kachaner J, et al. Detection of transposition of the great arteries in foetuses reduces neonatal morbidity and mortality. Circulation 1999;99:916-918.

9 Bull C. Current and potential impact of fetal diagnosis on prevalence and spectrum of serious congenital heart disease at term in the UK. Lancet 1999;354:1242-1247.

10 Cheatham JP. Intervention in the critically ill neonate and infant with hypoplastic left heart syndrome and intact atrial septum. J Interv Cardiol 2001;14:357-366.

11 Cohen MS, Rychik J. The small left ventricle: how small is too small for biventricular repair? Semin Thorac Cardiovasc Surg Pediatr Card Surg Annu 1999;2:189-202.

12 Cohen MS. Fetal diagnosis and management of congenital heart disease. Clin Perinatol 2001;28:11-29.

13 Deprest J, Gratacos E, Nicolaides KH; FETO Task 
Group. Fetoscopic tracheal occlusion (FETO) for severe congenital diaphragmatic hernia: evolution of a technique and preliminary results. Ultrasound Obstet Gynecol 2004; 24:121-126.

14 Ferencz C, Rubin JD, McCarter RJ, Brenner J, Neill CA, Perry LW, et al. Congenital heart disease: prevalence at livebirth. The Baltimore Washington infant study. Am J Epidemiol 1985;121:31-36.

15 Fasnacht M, Pfammatter JP, Ghisla R, Sekarski N, Steinmann $\mathrm{H}$, Kuen P, et al. FETCH study: prospective fetal cardiology study in Switzerland. Cardiol Young 2005;15(Suppl 2):35A.

16 Friedman AH, Kleinman CS, Copel JA. Diagnosis of cardiac defects: where we've been, where we are and where we're going. Prenat Diagn 2002;22:280-284.

17 Gardiner HM. Fetal echocardiography: 20 years of progress. Heart 2001;86 Suppl 2:II12-22.

18 Goldmuntz E, Bamford R, Karkera JD, dela Cruz J, Roessler E, Muenke M. CFC1 mutations in patients with transposition of the great arteries and double-outlet right ventricle. Am J Hum Genet 2002;70:776-780.

19 Hofbeck M, Beinder E, Kirchgessner G, Buheitel G, Singer H. Perinatal management of children with prenatal diagnosis of congenital heart defects. Z Geburtsh Neonatol 1997;201:49-54.

20 Hofbeck M, Rauch R, Beinder E, Buheitel G, Leipold G, Rauch A, et al. Rate of prenatal detection of congenital right heart defects. Z Geburtsh Neonatol 1999;203:207-212.

21 Hornberger LK, Sanders SP, Rein AJ, Spevak PJ, Parness IA, Colan SD. Left heart obstructive lesions and left ventricular growth in the midtrimester study. A longitudinal study. Circulation 1995;92:1531-1538.

22 Hornberger LK, Sanders SP, Sahn DJ, Rice MJ, Spevak PJ, Benacerraf BR, et al. In utero pulmonary artery and aortic growth and potential for progression of pulmonary outflow tract obstruction in tetralogy of Fallot. Am Coll Cardiol 1995;25:739-745.

23 Huhta J, Quintero RA, Suh E, Bader R. Advances in fetal cardiac intervention. Curr Opin Pediatr 2004;16:487-493.

24 Hyett J, Perdu M, Sharland G, Snijders R, Nicolaides KH. Using fetal nuchal translucency to screen for major congenital cardiac defects at 10-14 weeks of gestation: a population based cohort study. BMJ 1999;318:81-85.

25 Kohl T, Sharland G, Allan LD, Gembruch U, Chaoui R, Lopes LM, et al. World experience of percutaneous ultrasoundguided balloon valvuloplasty in human fetuses with severe aortic valve obstruction. Am J Cardiol 2000;85:1230-1233.

26 Kohl T. Fetal echocardiography: new grounds to explore during fetal cardiac intervention. Pediatr Cardiol 2002;23: 334-346.

27 Maeno YV, Boutin C, Hornberger L, McCrindle BW, CavalleGarrido T, Gladman G, et al. Prenatal diagnosis of right ventricular outflow tract obstruction with intact ventricular septum and detection of ventriculocoronary connections. Heart 1999;81:661-668.

28 Mahieu-Caputo D, Senat MV, Romana S, Houfflin-Debarge V, Gosset P, Audibert F, et al. What's new in fetal medicine? Arch Pediatr 2002;9:172-186.

29 Mennicke K, Schwinger E. Genetic aspects of congential heart defects. Gynäkologe 1997;30:181-189.

30 Meyer-Wittkopf M, Cooper S, Sholler G. Correlation between fetal cardiac diagnosis by obstetric and pediatric cardiologist sonographers and comparison with postnatal findings.
Ultrasound Obstet Gynecol 2001;17:392-397.

31 Meyer-Wittkopf M, Hofbeck M. Two- and three-dimensional echocardiographic analysis of congenital heart disease in the fetus. Herz 2003;28:240-249.

32 Meyer-Wittkopf M. Interventional fetal cardiac therapypossible perspectives and current shortcomings. Ultrasound Obstet Gynecol 2002;20:527-531.

33 Ott WJ. The accuracy of antenatal fetal echocardiography screening in high- and low-risk patients. Am J Obstet Gynecol 1995;172:1741-1749.

34 Quintero RA, Shukla AR, Homsy YL, Bukkapatnam R. Successful in utero endoscopic ablation of posterior urethral valves: a new dimension in fetal urology. Urology 2000;55: 774 .

35 Raupach K, Zimmermann R. False diagnosis in prenatal sonography-analysis of causes and formulation of conclusions for the quality management of prenatal sonographic diagnostics. Ultraschall Med 2004;25:438-443.

36 Simpson JM, Sharland GK. Natural history and outcome of aortic stenosis diagnosed prenatally. Heart 1997;77:205-210.

37 Sun C, Grumbach K, DeCosta D, Meyers C, Dungan J. Correlation of prenatal ultrasound diagnosis and pathologic findings in fetal anomalies. Pediatr Dev Pathol 1999;2:131-142.

38 Surbek DV, Holzgreve W, Nicolaides KH. Hematopoietic stem cells transplantation and gene therapy in the fetus: ready for clinical use? Hum Reprod Update 2001;7:85-91.

39 Tennstedt C, Chaoui R, Körner H, Dietel M. Spectrum of congenital heart defects and extracardiac malformations associated with chromosomal abnormalities: results of a seven year necropsy study. Heart 1999;82:34-39.

40 Tworetzky W, Marshall AC. Balloon valvuloplasty for congenital heart disease in the fetus. Clin Perinatol 2003;30: 541-550.

41 Ursell PC, Byrne JM, Fears TR, Strobino BA, Gersony WM. Growth of the great vessels in the normal human fetus and in the fetus with cardiac defects. Circulation 1991;84:2028-2033.

42 Ville Y, Hecher K, Gagnon A, Sebire N, Hyett J, Nicolaides $\mathrm{K}$. Endoscopic laser coagulation in the management of severe twin-to-twin transfusion syndrome. Br J Obstet Gynaecol 1998;105:446-453.

43 Walsh DS, Adzick NS, Sutton LN, Johnson MP. The Rationale for in utero repair of myelomeningocele. Fetal Diagn Ther 2001;16:312-322.

44 Walsh DS, Adzick NS. Fetal surgical intervention. Am J Perinatol 2000;17:277-283.

45 Weber HS. Initial and late results after catheter intervention for neonatal critical pulmonary valve stenosis and atresia with intact ventricular septum: a technique in continual evolution. Catheter Cardiovasc Interv 2002;56:394-399.

$46 \mathrm{Su} \mathrm{ZK}$, Chen E. Fetal cardiac surgery - a big challenge in the 21st century. World J Pediatr 2008;4:5-7.

47 Yagel S, Weissman A, Rotstein Z, Manor M, Hegesh J, Anteby $\mathrm{E}$, et al. Congenital heart defects. Natural course and in utero development. Circulation 1997;96:550-555.

48 Zimmermann R. The development of obstetric ultrasound in Switzerland. Gynakol Geburtshilfliche Rundsch 2005;45: 73-77.

Received July 29, 2008 Accepted after revision October 10, 2008 